\title{
Designing Algorithm for Malaria Diagnosis using Fuzzy Logic for Treatment (AMDFLT) in Ghana
}

\author{
Quashie Duodu \\ KNUST, Kumasi, Ghana \\ Department of Computer \\ Science
}

\author{
Joseph Kobina Panford \\ KNUST, Kumasi, Ghana \\ Department of Computer \\ Science
}

\author{
James Ben Hafron-Acquah \\ KNUST, Kumasi, Ghana \\ Department of Computer \\ Science
}

\begin{abstract}
Malaria is a dicey global healthmenace hence prompt attention to it is vital especially accurate diagnosis and immediate suitable treatment. The main objective of this study was to design algorithm for malaria diagnosis using fuzzy logic for treatment in Ghana. A case study was conducted in Juaso District Government Hospital (JDGH). Literature survey, observation, interview, patients' folder studies, and consultation were used fordata collection. The algorithm for malaria diagnosis and treatment using fuzzy logic (FL) was designed and simulated using MATLAB 7.8.0.Membership function and 27 fuzzy decision matrices were constructed and used. The algorithm was tested using thirteen randomly sampled malaria suspected patients in JDGH.The designed algorithm gives $15.4 \%$ accurate diagnosis result more than the result of the presumptive medical doctors' diagnosis. Fuzzy logic is a very useful tool in dealing accurately with problems that appear to be solved only by human judgment when data is modeled well.
\end{abstract}

\section{General Terms:}

Fuzzy logic, algorithm, membership function, fuzzy decision matrix, linguistic variable

\section{INTRODUCTION}

Malaria is a dangerousglobalhealth problem hence accurate diagnosisand suitable treatment is needed to curb it [1]. Nearly $300-500$ million malaria cases is recorded, resulting in 2 million deaths annually. According to the Ghana Health Service (GHS) health facility data, malaria is the number one cause of morbidity, accounting for about $38 \%$ of all outpatient illnesses, $36 \%$ of all admissions, and 33\% of all deaths in children below five years. Malaria is the highest cause of death in health institutions with mortality rate of $17.1 \%$ [3].

The effects of malaria as disease is unbearable. These include direct costs for treatment and prevention; time spent seeking treatment, and diversion of household resources for treatment. Malaria accounted for an average loss of $1.3 \%$ of economic growth annually in countrieswhere transmission is high as a control, medical instrumentation, Decision-Support Systems (DSS), and portfolio selection. FL algorithms can be used for advanced applications in industrial automation such as: intelligent control systems, process diagnostics, fault detection, and decision-making and expert systems. In this particular work, FL is used for malaria diagnosis. The following explain why fuzzy logic is used in most systems. It is conceptually easy to understand, is flexible, is tolerant of imprecise data, it can be built on top of the experience of experts, and it is based on natural language. result of a decline in productivity and the annual economic burden of malaria is estimated 1-2 per cent of the Gross Domestic Product (GPD) in Ghana [2].Effective Case Management (ECM) is critical for the reduction of malaria morbidity and mortality in sub-Saharan Africa [4]. However, ECM relies solely on early identification of symptoms[5]. With increasing anti-malarial drug costs, diagnostic methods are crucial in malaria control and prevention. This research is aimed at designing Algorithm for Malaria Diagnosis using Fuzzy Logic for Treatment (AMDFLT) in Ghana.

\section{FUZZY LOGIC}

Fuzzy logic began with the 1965 proposal of fuzzy set theory by Prof. LotfiZadeh [6], [7]. Fuzzy logic (FL) is almost the same as fuzzy sets theory, a theory which relates to group of objects with unclear boundaries in which membership is a matter of degree [8]. FL is a form of many-valued logic or probabilistic logic; it concerns with reasoning that is approximate instead of fixed and exact [9].

Fuzzy sets were introduced by Prof. L. A. Zadeh in 1965 as an extension of the traditional idea of set. A fuzzy set A in X is expressed as a set of ordered pairs:

$A=\{(x, \mu A(x)) \mid x \in X\}$

where $\mu \mathrm{A}$ is called the membership function,

$\mu A: X \longrightarrow M$

where $\mathrm{M}$ is the membership space where each element of $\mathrm{X}$ is mapped to.

If $M=\{0,1\}, A$ is a crisp set.

However, if $\{0 \leq M \geq 1\}$, A is a fuzzy set.

FL has been applied in many fields, from control theory to artificial intelligence. The applications range from consumer products such as cameras, camcorders, washing machines, and

microwave ovens to industrial process

\section{METHODOLOGY}

\subsection{Data Collection}

This research is a case study conducted in Juaso District Government Hospital in Ghana. Literature survey, observation, interview, patients' folder studies and consultation were used for gathering data to unearth the hospitals' need and also establish the requirement of the algorithm, decide on input and output linguistic variables, construct membership function, and design fuzzy decision matrices. Purposive sampling method was used to select 3 medical personnel. Random sampling method was used for the selection of 13patients. Tools such as activitydiagram, casediagram,algorithm,flowchart, and MATLAB 7.8.0 were used. 


\subsection{Model of the Existing Medical Doctors' Diagnosis}

Fig 1 shows how themedical doctors' diagnosis model is used to diagnose malaria.

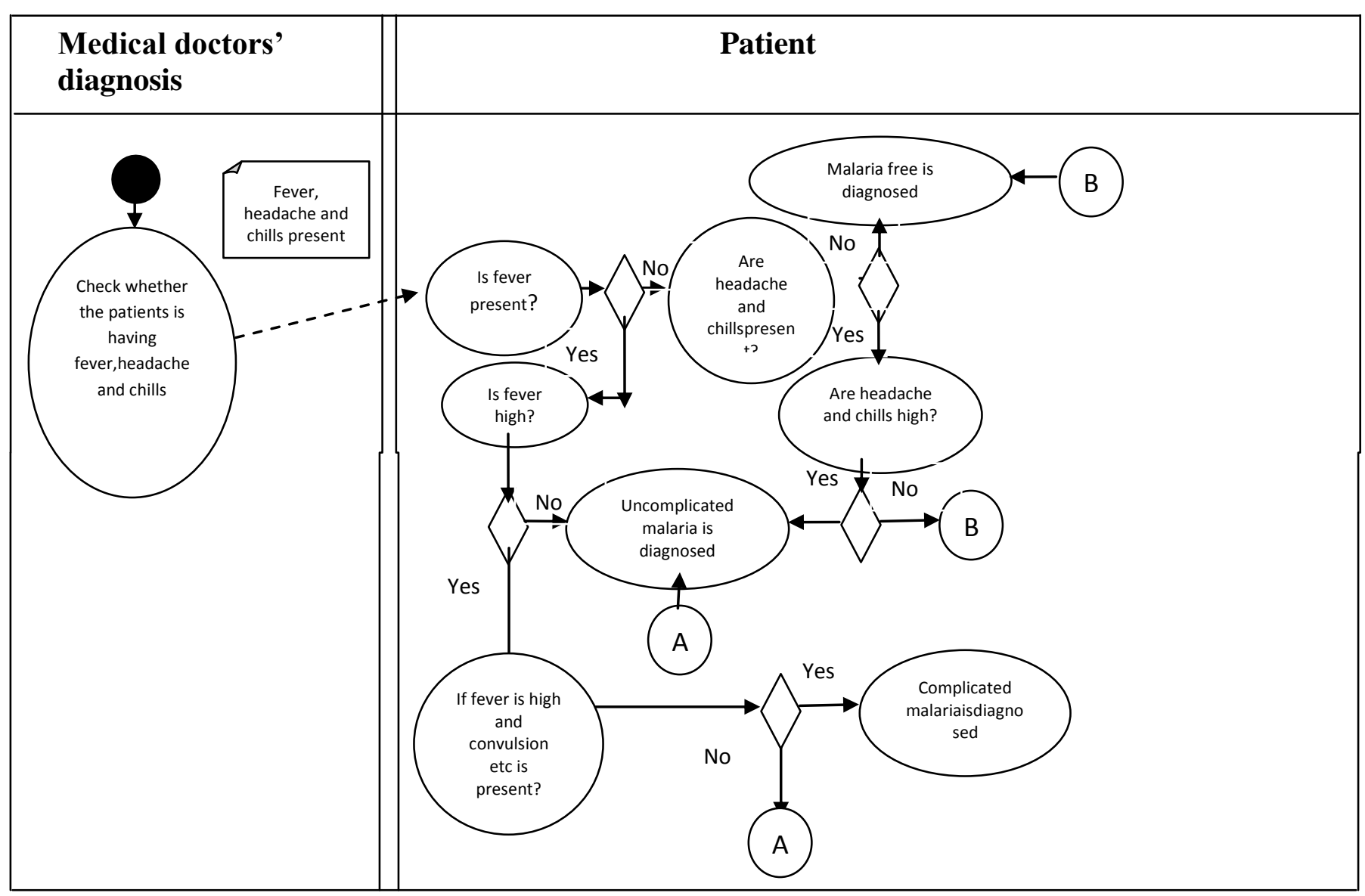

Fig 1: Model of the existing medical doctors' diagnosis 


\subsection{Model of the Designed Algorithm Diagnosis}

Fig2 shows the model of how the designed algorithm is used to diagnose malaria.

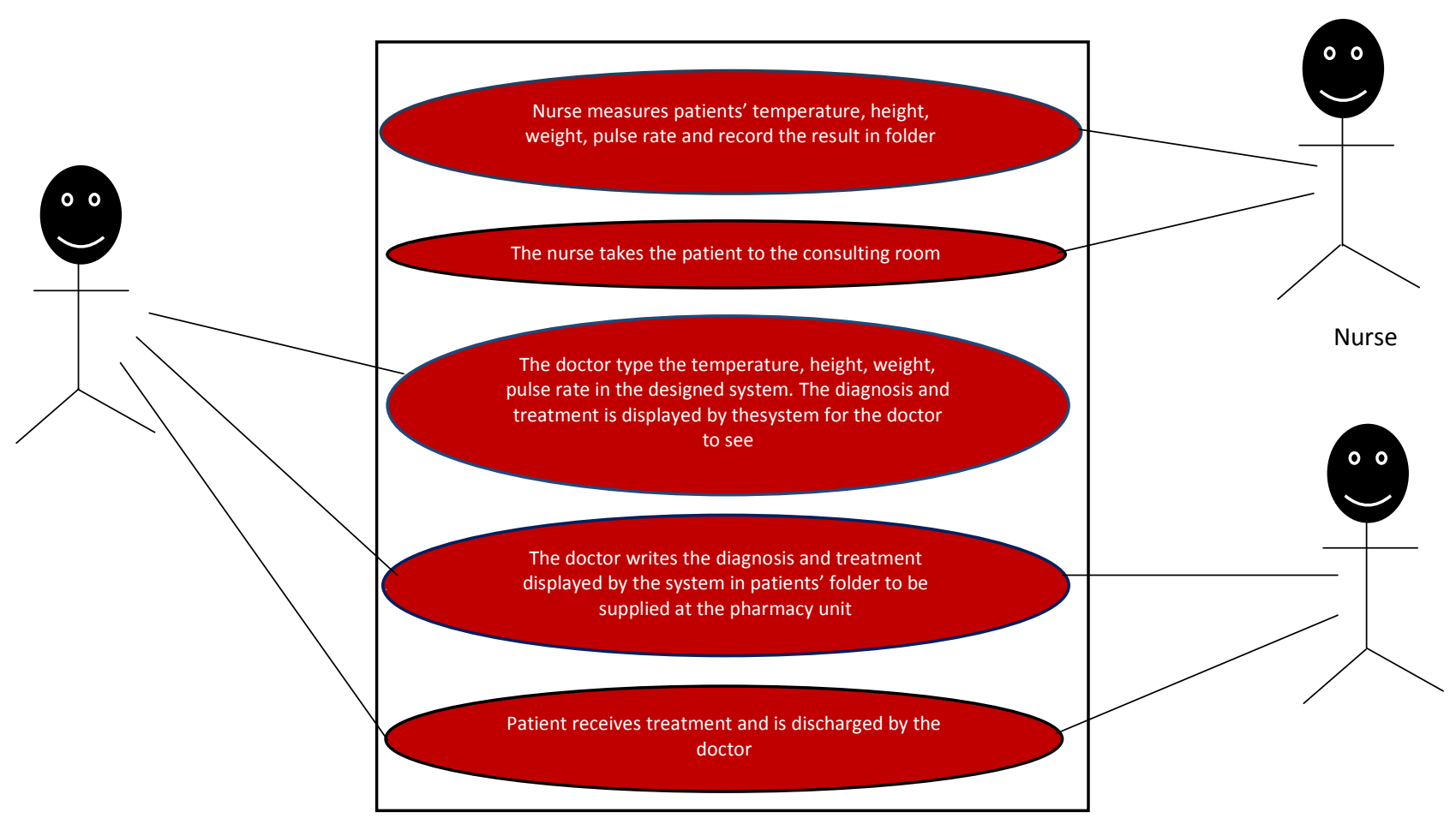

Fig2: Model of the designed algorithm diagnosis

\subsection{Criticism of the Existing Medical \\ Doctors' Diagnosis}

The following are loop-hole identified in the existing model: guessing of intensity values for the malaria predictors, overreliance of patients complainsleading to inaccurate diagnosis and delay, medical doctor have to search through his or her knowledge and sometimes consult books causing delay, feelings and mood of the doctor may affect the diagnosis. The designed algorithm on the other hand makes use of temperature, BMI, and pulse rate measured by a nurse. There is reduction of time spent on patients in consulting rooms because the practitioners only enter the intensity values of the symptom to receive the result. Again, there is a removal of human feelings and

mood in the malaria diagnosis and treatment 


\section{IMPLEMENTATION}

\subsection{Structure of the Fuzzy System}

The AMDFLT architecture shown in fig3 consists of four main components, namely fuzzification, Data-store, inference engine and defuzzification. Two other components of the system are input data and output.

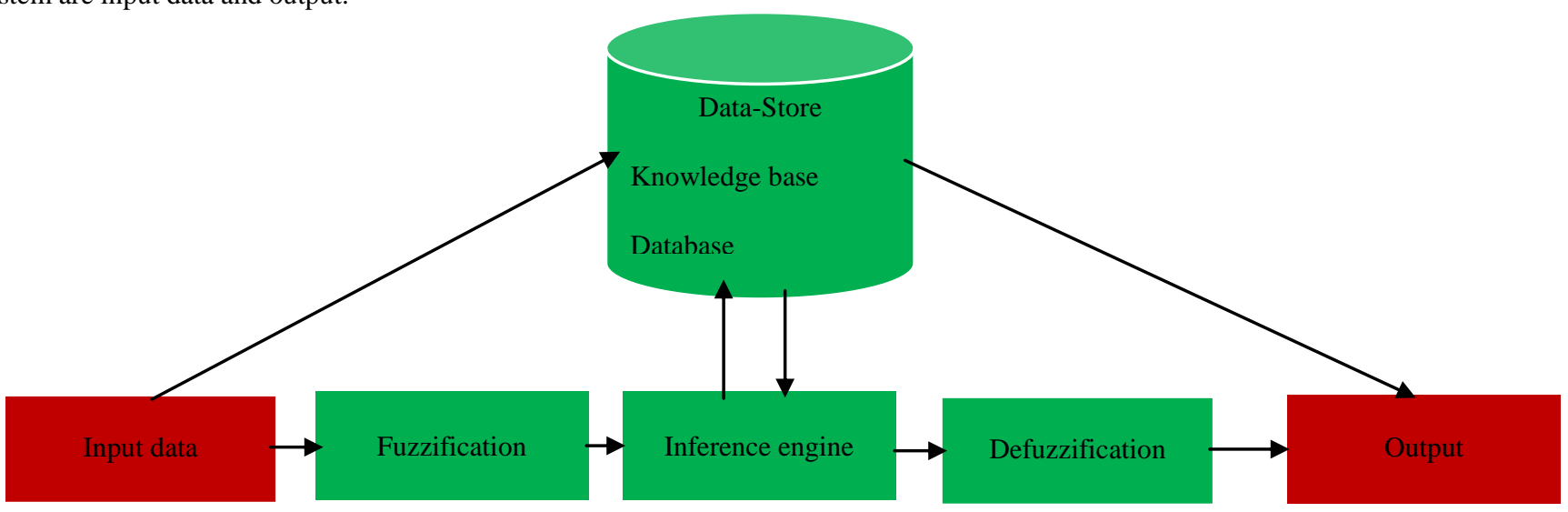

Fig 3: Architectural Structure of the Fuzzy System

\subsubsection{Input data}

This component receives data into the system using input technology like keyboard. The user reads the exact number taken from the instruments for measuring the patients' temperature, height, weight and pulse rate in Celsius (C), meters $(\mathrm{m})$, kilograms $(\mathrm{Kg})$ and BPM respectively. The converted intensity values are determined in $100 \%$ and entered.

\subsubsection{Fuzzification}

In fuzzification, the crisp input values are converted to membership degrees, by applying the corresponding membership functions (fuzzifier). Mathematically,

$x=$ fuzzifier $\left(x_{0}\right)$

where $\mathrm{x}_{\mathrm{o}}$ is a crisp input value, $\mathrm{x}$ is the corresponding fuzzy set, and fuzzifier represent a fuzzification function. Three symptoms were used as the fuzzy input variables namely temperature, BMI and pulse rate. Each fuzzy input variable is fuzzified using three linguistic values namely low, medium and high. Triangular membership function is used. Membership function of symptom input variable temperature, BMI and Pulse rate generated from MATLAB 7.8.0 (R2009a) are shown in fig 4, 5, and 6 respectively.

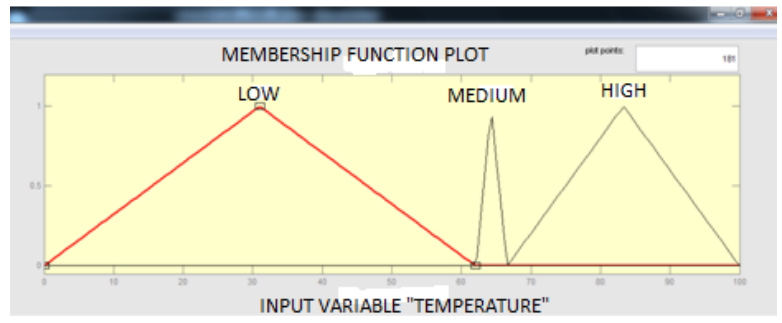

Fig 4: Membership function of temperature

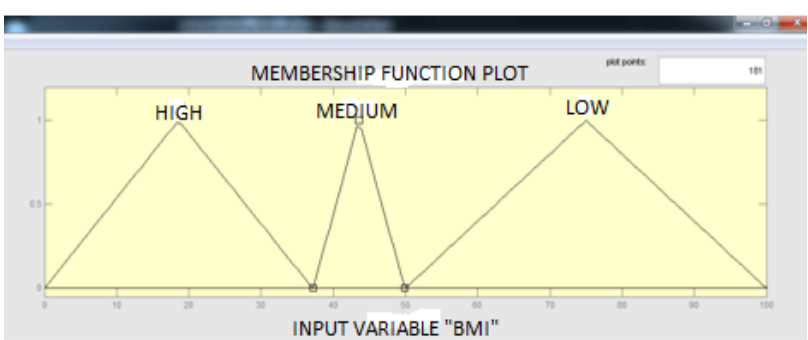

Fig5: Membership function of BMI

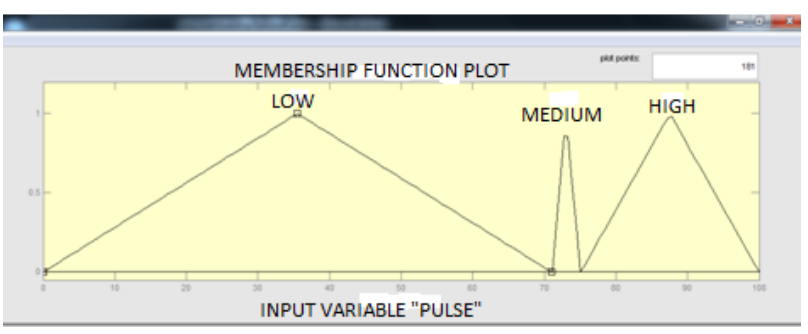

Fig6: Membership function of Pulse rate

\subsubsection{Data-store}

This component contains the Knowledge Base (KB) and the Database. The KB was captured from the medical experts and malaria books review. The KB consists of a set of IF-THEN decision matrices constructed using logical AND operator and forward chaining; and stored in the data-store for references by the inference engine.The database stores the patients' health history for future reference.

\subsubsection{Inference engine}

In the inference engine, fuzzified input is then matched with the rules and a set of fuzzy actions are generated. Sample of the rules are shown below:

DT1:If min(temperature(low), BMI(low), pulse rate(low)) then diagnosis= "malaria free" and treatment="discharge patient without medication" 
DT2: If min(temperature(medium), BMI(medium), pulse rate(low)) then diagnosis="uncomplicated malaria" and treatment="Artesunate tablet orAmodiaquine syrup"

\subsubsection{Defuzzification}

The aim of defuzzification is to generate a crisp value that will be representative of the output from the inference engine. Centre- of -Gravity method is used. This is because

CoGdefuzzification method is simple and requires less computation effort compared to MOM, MAX, HD and CoS The general function of $\mathrm{CoG}$ is given as:

$$
\operatorname{CoG}=\frac{\sum \square_{y}\left(x_{i}\right) x_{i}}{\sum \square_{y}\left(x_{i}\right)}
$$

Where $\Omega_{y}\left(x_{i}\right)=$ Membership value in the membership function and $x_{i}=$ center of membership function.

\subsubsection{Output of the system}

There are two output of this system, namely diagnosis and treatment.The membership function of the diagnosis and treatment output variables are shown in fig 7 and 8 respectively.

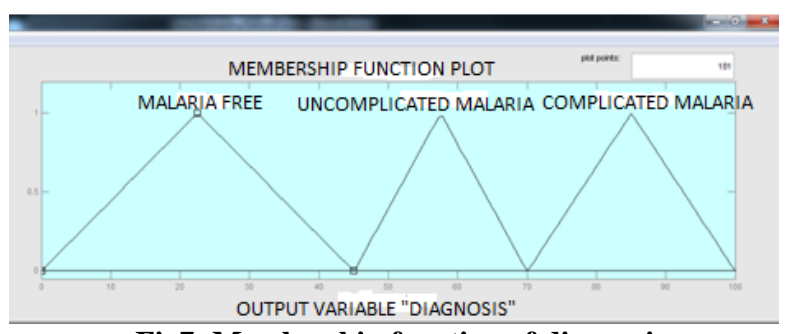

Fig7: Membership function of diagnosis

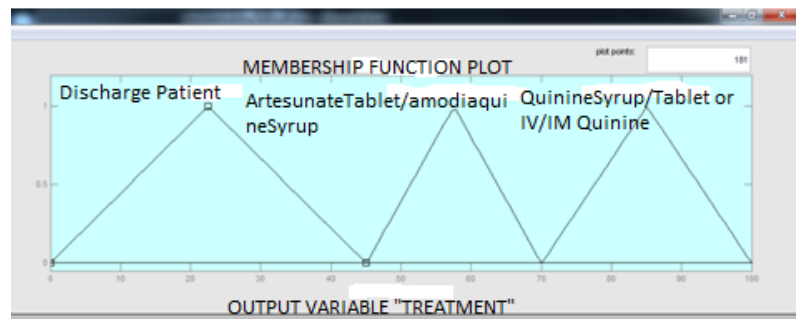

Fig8: Membership function of treatment

\subsection{The Algorithm}

The designed algorithm used is as follows:

1. Typepatients' ID;

2. If the ID is already in the data base then

Read name, age, and gender from the database;

Else

Type name, age and gender;

3. Type the temperature, weight, height, and pulse rate;

4. Calculate $B M I=$ weight $/(\text { height })^{2}$;
5. Evaluate the symptoms against the fuzzy rule in the knowledge base;

Choose appropriate linguistic variables for the symptoms' input variable and construct fuzzy membership function;

Construct fuzzy decision matrix (rule) as the knowledge base of the system;

Match the input variable to the fuzzy rule in the knowledge base;

Determine whether there is malaria;

6. If malaria then

Prescribe a drug based on the degree of infection;

Else

Give "malaria free" as message;

7. Stop.

\subsection{The Flowchart of the Algorithm}

The flowchart of the algorithm is shown in fig9

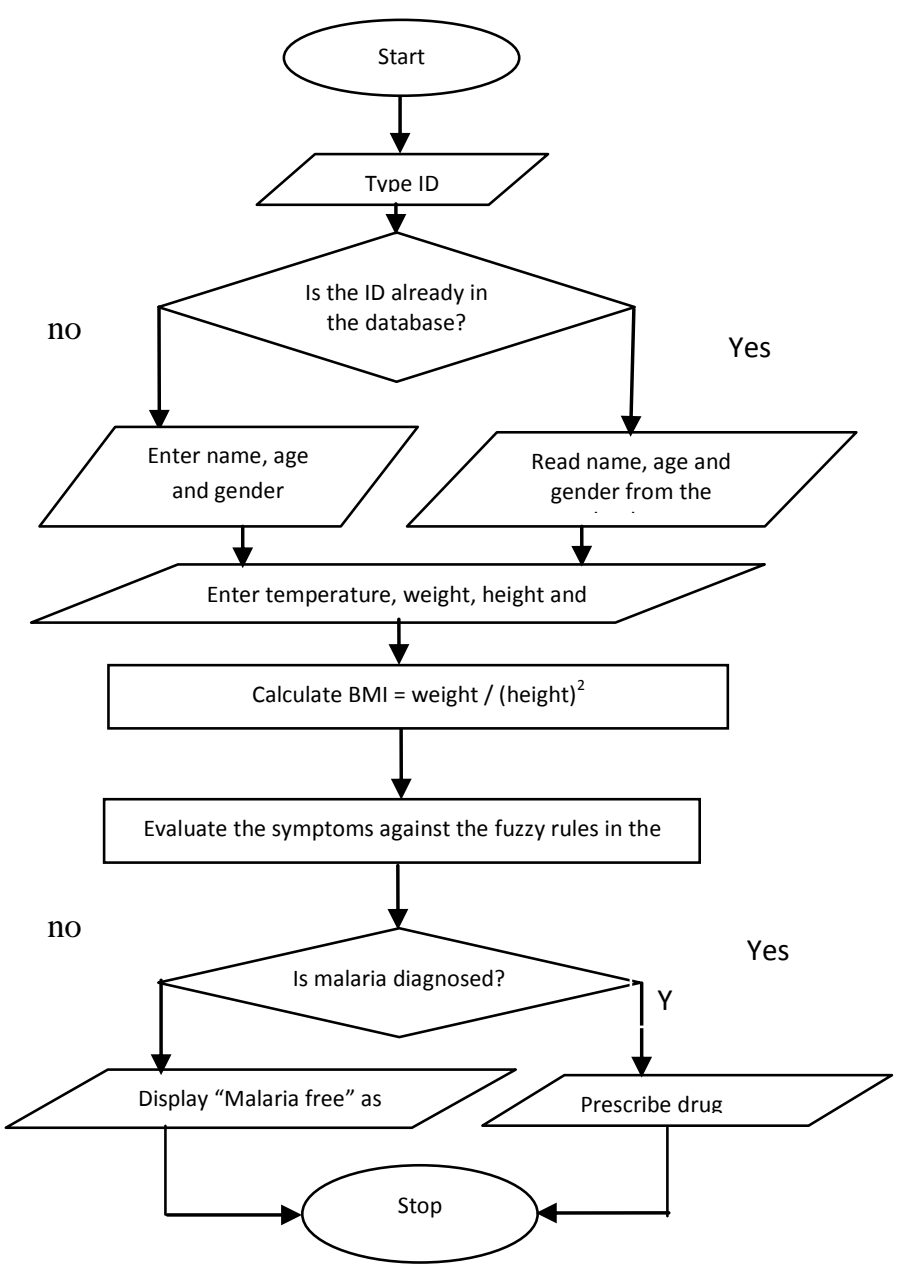

Fig9: Flowchart of the Algorithm 


\subsection{Simulation of the Designed Algorithm}

The algorithm was simulated usingMATLAB 7.8.0 (R2009a). The rule editor of the malaria FIS is shown in fig 10

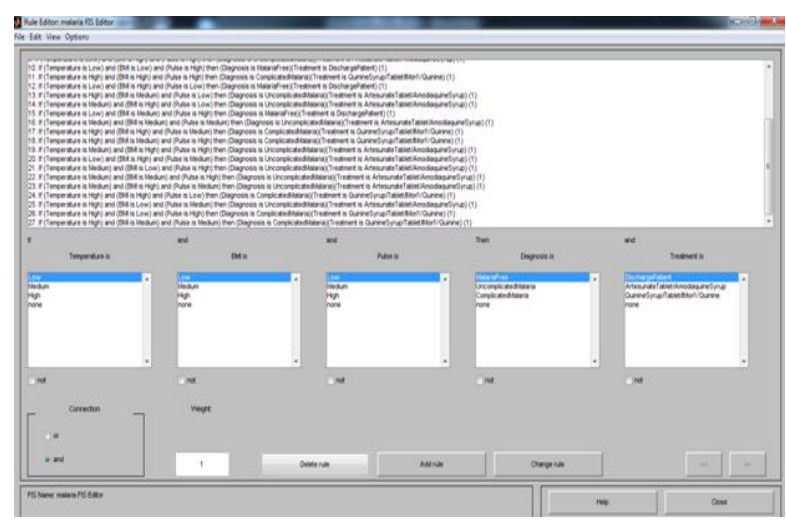

Fig10: The rule editor of the malaria FIS

\subsection{Experimentation}

Running test using randomly sampled thirteen patients who had earlier gone through medical doctors' diagnosis and laboratory diagnosis was carried out.

\subsection{Comparing Experimentation Results}

The objective here is to compare medical doctors' diagnosis with the designed algorithm using laboratory diagnosis as accurate and standard diagnosis. Out of 13 patients used, the medical doctors' diagnosis had 8 correct diagnoses whereas the designed algorithm diagnosis had 10 correct diagnoses. Table1 shows results of diagnosis from medical doctor, laboratory diagnosis and the algorithm diagnosis.

Table 1: Results of diagnosis from medical doctor, laboratory diagnosis and the algorithm diagnosis

\begin{tabular}{|l|l|l|l|}
\hline $\begin{array}{l}\text { PATIENTS } \\
\text { ID }\end{array}$ & $\begin{array}{l}\text { MEDICAL } \\
\text { DOCTORS' } \\
\text { DIAGNOSIS }\end{array}$ & $\begin{array}{l}\text { LABORATORY } \\
\text { DIAGNOSIS }\end{array}$ & $\begin{array}{l}\text { DESIGNED } \\
\text { ALGORITHM } \\
\text { DIAGNOSIS }\end{array}$ \\
\hline $\begin{array}{l}\text { AAS001-03- } \\
02-13\end{array}$ & Malaria free & $\begin{array}{l}\text { Uncomplicated } \\
\text { malaria }\end{array}$ & $\begin{array}{l}\text { Uncomplicated } \\
\text { malaria }\end{array}$ \\
\hline $\begin{array}{l}\text { AAS002-03- } \\
02-13\end{array}$ & $\begin{array}{l}\text { Uncomplicated } \\
\text { malaria }\end{array}$ & $\begin{array}{l}\text { Uncomplicated } \\
\text { malaria }\end{array}$ & $\begin{array}{l}\text { Uncomplicated } \\
\text { malaria }\end{array}$ \\
\hline $\begin{array}{l}\text { AAS003-03- } \\
02-13\end{array}$ & $\begin{array}{l}\text { Uncomplicated } \\
\text { malaria }\end{array}$ & Malaria free & Malaria free \\
\hline $\begin{array}{l}\text { AAS004-03- } \\
02-13\end{array}$ & $\begin{array}{l}\text { Uncomplicated } \\
\text { malaria }\end{array}$ & $\begin{array}{l}\text { Uncomplicated } \\
\text { malaria }\end{array}$ & $\begin{array}{l}\text { Complicated } \\
\text { malaria }\end{array}$ \\
\hline $\begin{array}{l}\text { AAS005-03- } \\
02-13\end{array}$ & $\begin{array}{l}\text { Uncomplicated } \\
\text { malaria }\end{array}$ & $\begin{array}{l}\text { Uncomplicated } \\
\text { malaria }\end{array}$ & $\begin{array}{l}\text { Uncomplicated } \\
\text { malaria }\end{array}$ \\
\hline $\begin{array}{l}\text { AAS006-16- } \\
09-13\end{array}$ & Malaria free & $\begin{array}{l}\text { Complicated } \\
\text { malaria }\end{array}$ & $\begin{array}{l}\text { Uncomplicated } \\
\text { malaria }\end{array}$ \\
\hline $\begin{array}{l}\text { AAS007-16- } \\
09-13\end{array}$ & $\begin{array}{l}\text { Uncomplicated } \\
\text { malaria }\end{array}$ & $\begin{array}{l}\text { Uncomplicated } \\
\text { malaria }\end{array}$ & $\begin{array}{l}\text { Uncomplicated } \\
\text { malaria }\end{array}$ \\
\hline $\begin{array}{l}\text { AAS008-16- } \\
09-13\end{array}$ & Uncomplicated & $\begin{array}{l}\text { Uncomplicated } \\
\text { malaria }\end{array}$ & $\begin{array}{l}\text { Uncomplicated } \\
\text { malaria }\end{array}$ \\
\hline $\begin{array}{l}\text { AAS009-16- } \\
09-13\end{array}$ & Malaria free & $\begin{array}{l}\text { Uncomplicated } \\
\text { malaria }\end{array}$ & $\begin{array}{l}\text { Uncomplicated } \\
\text { malaria }\end{array}$ \\
\hline $\begin{array}{l}\text { AAS010-16- } \\
09-13\end{array}$ & $\begin{array}{l}\text { Uncomplicated } \\
\text { malaria }\end{array}$ & $\begin{array}{l}\text { Uncomplicated } \\
\text { malaria }\end{array}$ & $\begin{array}{l}\text { Uncomplicated } \\
\text { malaria }\end{array}$ \\
\hline $\begin{array}{l}\text { AAS011-16- } \\
09-13\end{array}$ & $\begin{array}{l}\text { Uncomplicated } \\
\text { malaria }\end{array}$ & $\begin{array}{l}\text { Uncomplicated } \\
\text { malaria }\end{array}$ & Malaria free \\
\hline $\begin{array}{l}\text { AAS012-16- } \\
09-13\end{array}$ & $\begin{array}{l}\text { Uncomplicated } \\
\text { malaria }\end{array}$ & Malaria free & Malaria free \\
\hline $\begin{array}{l}\text { AAS013-16- } \\
09-13\end{array}$ & Uncomplicated \\
malaria & $\begin{array}{l}\text { Uncomplicated } \\
\text { malaria }\end{array}$ & $\begin{array}{l}\text { Uncomplicated } \\
\text { malaria }\end{array}$ \\
\hline & & \\
\hline
\end{tabular}

\subsection{Discussion of the Results}

Using laboratory diagnosis as a standard for the comparison,percentage accuracy was measured as:

$$
(\text { Correctdiagnosis }) /(\text { Totaldiagnosis }) \times 100
$$

In comparison, the percentage accuracy of medical doctors' diagnosis is $8 / 13 \times 100$ which is $61.5 \%$ whereas the designed algorithm is $10 / 13 \times 100$ which is $76.9 \%$ given a difference of $15.4 \%$ accuracy. The medical doctors' diagnosis is solely based on guess work where the doctor makes malaria diagnosis by observing and conversing with patients. This explains why error was introduced in the diagnosis leading to the $15.4 \%$ inaccuracy compared to AMDFLT. The designed diagnosis algorithm is based on scientific approach because malaria predictors were measured using scientific measuring instruments and standard SI units. This eliminates guessing of intensity values to the predictors and subjective human factor.

\subsection{Conclusion}

Fuzzy logic is a very useful tool in dealing accurately with problems that appear to be solved only by human judgment when data is modeled well.

\subsection{Recommendations}

It is recommended that fuzzy logic algorithm be made available for use in hospitals and clinics in Ghana. The hospitals should get enough storage media to keep the database of patients to serve as patients' health history for future use. This database can be cross-referenced among health facilities.

\subsection{Suggested Future Work}

Clinical algorithm needs to be developed for malaria diagnosis in Ghana rather than using the IMCI developed by WHO since signs and symptoms for malaria diagnosis is area specific. Again research into fuzzy logic system that would be able to diagnose all diseases to eliminate guessdiagnosis in clinics and hospitals should be carried out.

\section{REFERENCES}

[1] Nicholas E.R., Charles J.P., David M.R., and Adraino G.D:" Automated Image Processing Method for the Diagnosis and Classification of Malaria on ThinBlood Smears", International Federation for Medicalan Biological Engineering, 2006, DOI 10.1007/s11517-0060044-2, http://link.springer.com/content/pdf(accessed 2012, Oct. 15)

[2] UNICEF Ghana Fact Sheet: "Malaria", UNICEF, July 2007 ,

www.unicef.org/wcaro/WCARO_Ghana_Factsheet_malaria.pdf (accessed2012,Aug,15)

[3] GHS (2004): "Annual Report", www.ghanahealthservice.org/ includes/upload publications, (accessed 2012,Aug,14)

[4] WHO (1993): "Implementationof the global malaria control strategy". WHO Technical Report Series 839. WHO, Geneva, http://whqlibdoc.who.int/publications/9241561610.pdf (accessed 2012, Oct, 15) 
[5] Chandramohan D., Carneiro I.,Kavishwar A.,Brugha R, Desai V.and Greenwood B: "A clinical algorithm for the diagnosis of malaria: results of an evaluation in an area of low endemicity", London School of Hygiene and Tropical Medicine, London, UK and Department of Preventive andSocial Medicine, GovernmentMedical College, Surat, India, Tropical Medicine and International Health, volume 6 no7 pp 505-510 July 001,www.ncbi.nlm.nih.gov/pubmed/11469942(accessed 2012, Nov, 23)

[6] "Fuzzy Logic", Stanford Encyclopedia ofPhilosophy,Stanford University. 2006-07-23,http:// plato. stanford. Edu / entries / logic-fuzzy (accessed 2012,May, 07)

[7] Zadeh, L.A. (1965): "Fuzzy sets, Information and Control"s
bisc.cs.berkeley.edu/Zadeh-1965.pdf (accessed 2012, May 07)

[8] Fuzzy Logic Toolbox ${ }^{\text {TM }}$ User's Guide R2012a (2012), The Inc.www.mathworks.com/trademarks/pdf (accessed2012,May,07)

[9] Wikipedia, the freeencyclopedia, http://en.wikipedia.org/wiki/MATLAB(accessed 2012 May 07)

[10] Djam X.Y., and Kimbi Y. H.: "A MedicalDiagnostic support System For The Management Of Hypertension", Journal of Medical and Applied Biosciences, Volume 3, March 2011, Cenresin Publications, http://medapl/cen?hypertension/pdf (accessed2012, Nov. 09) 